\title{
AVALIAÇÃO DA ATIVIDADE BACTERIOCINOGÊNICA DO Lactobacillus sakei NA FERMENTAÇÃO DA SARDINHA-VERDADEIRA (Sardinella brasiliensis) UTILIZANDO GLICOSE COMO CARBOIDRATO FERMENTECÍVEL
}

\author{
MILTON LUIZ PINHO ESPÍRITO SANTO * \\ LUIZ HENRIQUE BEIRÃO ** \\ ERNANI SANT'ANNA ** \\ CESAR DAMIAN *** \\ BERNADETTE MELLO FRANCO ****
}

\begin{abstract}
Lactobacillus sakeié comprovadamente uma cepa produtora de bacteriocinas e, neste estudo, procurou-se observar seus efeitos na fermentação de filés de sardinha (Sardinella brasiliensis) em diferentes concentrações de $\mathrm{NaCl}$ e glicose. Verificou-se sua habilidade para produzir ácidos orgânicos e conseqüente redução do $\mathrm{pH}$ durante 21 dias de fermentação. Ao término desse período, a concentração de microrganismos deterioradores atingiu 9,7 log UFC g ${ }^{-1}$ correspondente a $6 \%$ de $\mathrm{NaCl}$ e $4 \%$ de glicose. Poucas diferenças foram observadas na produção de ácido lático quando se adicionou 2 e $4 \%$ de glicose, já que a acidez total foi 1,32 e $1,34 \%$, respectivamente, para os experimentos com $6 \%$ de $\mathrm{NaCl}$. O pH 6 inicial dos filés modificou-se ao término de 21 dias para 3,8, 3,9 e 4 nos experimentos com 2, 4 e $6 \%$ de $\mathrm{NaCl}$. Tal comportamento pode ser atribuído ao poder inibidor do $\mathrm{NaCl}$ sobre a microbiota deterioradora. No término da fermentação, a concentração de bactérias ácido lácticas foi $14,5 \log _{10}$ UFC g-1. A relação entre o nitrogênio protéico e o nitrogênio solúvel total mostrou-se típica de pescado salgado/curado em perfeitas condições de consumo.
\end{abstract}

PALAVRAS-CHAVE: FILÉS DE SARDINHA-FERMENTAÇÃO; PESCADO SALGADO; Lactobacillus sakei.

* $\quad$ Professor Adjunto, Departamento de Química, Fundação Universidade Federal do Rio Grande, RS. (e-mail: mes@vetorial.net).

** Professor Titular, Centro de Ciências Agrárias, Universidade Federal de Santa Catarina (UFSC), SC. (e-mail: ernanis@cca.ufsc.br).

Professor Assistente, Departamento de Ciência e Tecnologia de Alimentos, UFSC, SC. (e-mail: cdamian@cca.ufsc.br).

Professora Titular, Departamento de Alimentos e Nutrição Experimental, Faculdade de Farmácia, Universidade de São Paulo, SP. 


\section{INTRODUÇÃO}

Embora existam inúmeras técnicas mais eficientes para preservação do pescado, ainda se faz uso da salga e fermentação para obter produto diferenciado nos seus aspectos físico-sensoriais.

Um dos grandes inconvenientes nos produtos salgados e fermentados é 0 alto teor de $\mathrm{NaCl}$ que, invariavelmente, implica em dessalga (PIGOTT e TUCKER, 1990). As proteínas do pescado, quando comparadas com as de outros animais, apresentam conservação quase sempre acompanhada de difícil contenção das alterações deterioradoras (ROBINSON, 1991). Entretanto, quando essas transformações são controladas passam a ser benéficas produzindo flavour o odores apropriados, mascarando o sabor indesejável de algumas espécies e aumentando a aceitabilidade de outras (ROIG-SAGUÉS e EEROLA, 1997; LISTON, 1979). Na América do Sul, países como Peru, Chile e Argentina desenvolveram fermentações de anchovas (Pomatomus saltator), nas quais os peixes são misturados com $\mathrm{NaCl}$ na proporção de $30 \%$ e processados por fermentações que podem durar até 4 meses (LINDEN e LORIENT, 1994; BRASIL, 1998). Na Europa, os exemplos de produtos pesqueiros fermentados são encontrados na Escandinávia. Entre as espécies utilizadas encontramse o arenque (Clupea harengus), o salmão (Salmo salar) e a truta (Salmo truta), que produzem fermentados como o gaffelbi ou o tidbits, o gravlax e o rakorett, respectivamente. Inúmeros estudos têm demonstrado que a introdução de fermentação anaeróbica, associada à bactérias ácido lácticas é capaz de interromper temporariamente ou definitivamente os processos bioquímicos oxidativos e a deterioração microbiana (MAZO, 1999). Procurou-se avaliar, neste trabalho, a bacteriocinogenicidade do starter formado pelo Lactobacillus sakei 2 a e o seu efeito na qualidade microbiológica da sardinha-verdadeira (Sadinella brasiliensis), com ênfase na sua atividade contra as bactérias deterioradoras associadas ao processo fermentativo.

\section{MATERIAL E MÉTODOS}

Filés de sardinha (Sardinella brasiliensis) foram preparados a partir de 3 lotes de peixes inteiros e armazenados a $-18^{\circ} \mathrm{C}$. Os experimentos foram realizados em níveis de 2 , 4 e $6 \%$ de $\mathrm{NaCl}$ com adição de 2 e $4 \%$ de glicose. Os tratamentos foram desenvolvidos de forma independente, variando-se apenas um dos parâmetros operacionais ( $\mathrm{NaCl}$ ou glicose). Em todos os tratamentos foram adicionados inóculos $\left(8,0 \log _{10} \mathrm{UFC} \mathrm{mL}-1\right)$ 
de Lactobacillus sakei 2a. O processo desenvolveu-se na condição de salga úmida na proporção de 1:1, ou seja, $300 \mathrm{~g}$ de filés para $300 \mathrm{~mL}$ de salmoura.

Como cultivo iniciador utilizou-se a cepa Lactobacillus sakei 2a, isolada de lingüiça frescal (DE MARTINIS e FRANCO, 1998). Alíquotas de $1 \mathrm{~mL}$ da cultura foram mantidas a $-80^{\circ} \mathrm{C}$ em caldo MRS, formulado com $5 \%$ de glicose. Antes da utilização, as culturas foram reativadas em caldo MRS com incubação a $30{ }^{\circ} \mathrm{C}$ por 18 horas. Caracterizou-se o Lactobacillus sakei 2a mediante estudo morfológico em meio sólido pela descrição visual da colônia isolada em ágar MRS. A observação microscópica baseouse na forma, arranjo e coloração diferencial de Gram. A caracterização fisiológica foi determinada pelo crescimento em $\mathrm{pH}$ 3,9 e temperaturas diferenciadas $\left(8,15\right.$ e $\left.45^{\circ} \mathrm{C}\right)$, halofilismo em distintas concentrações salinas $(6,5,7$ e $10 \% \mathrm{NaCl})$ e liquefação da gelatina com leitura até 7 dias (FAO, 1993; SILVA et al., 1997). Como teste complementar determinouse o requerimento de oxigênio e a motilidade em meio semi-sólido (SILVA et al., 1997). A linhagem foi caracterizada bioquimicamente pelos seguintes ensaios: teste da catalase, produção de acetoína, prova do vermelho de metila, produção de $\mathrm{H}_{2} \mathrm{~S}$, gás de glicose, descarboxilação da lisina, produção de indol e fermentação de carboidratos (sacarose, glicose, arabinose, galactose, maltose, lactose, ramnose, trealose, sorbitol, rafinose e xilose). As amostras foram incubadas a temperatura de $30^{\circ} \mathrm{C}$ e os resultados verificados até 7 dias (ICMSF, 1990). A produção de bacteriocinas foi detectada pela técnica da difusão em poços (well diffusion-assay) (DE MARTINIS e FRANCO, 1998). A ativação e preparação do inóculo foram realizadas em caldo MRS. Após a incubação $\left(30^{\circ} \mathrm{C}\right.$ por 18 horas) procedeu-se à ressuspensão de alíquota de $5 \mathrm{~mL}$ em $200 \mathrm{~mL}$ de caldo MRS com incubação a $30^{\circ} \mathrm{C}$ por 12 horas. Posteriormente, porções de $10 \mathrm{~mL}$ da cultura ativada (carga celular de Lactobacillus sakei 2a equivalente a $8,0 \log _{10}$ UFC $\mathrm{mL}^{-1}$ ) foram transferidas para as cubas de fermentação correspondentes aos tratamentos estabelecidos. A determinação da concentração celular do inóculo foi estimada por espectrofotometria a $520 \mathrm{~nm}$, sendo as alíquotas para as leituras de absorbância centrifugadas a $9,77 \times$ g por 10 minutos. O sobrenadante foi descartado e o precipitado ressuspenso em $3 \mathrm{~mL}$ de água peptonada $1 \%$, adicionada de $3 \mathrm{~mL}$ de solução de EDTA 1\% e alcalinizada com $\mathrm{NaOH}$ 10M (DE MARTINIS e FRANCO, 1998).

Realizou-se a avaliação do número de células viáveis do inóculo em ágar MRS. As determinações microbiológicas correspondentes à contagem total de microrganismos aeróbios mesófilos, bactérias ácido lácticas, 
coliformes fecais, Staphylococcus aureus, Enterococcus e detecção de Salmonella sp. foram efetuadas segundo a APHA (1992).

A determinação da composição centesimal da matéria-prima foi realizada segundo técnicas da AOAC (1995), umidade e cinzas por gravimetria, proteínas pelo método micro-Kjeldahl e extrato etéreo (submersão) por extração com éter de petróleo.

Os caldos de fermentação tiveram seus conteúdos de nitrogênio solúvel total e protéico determinados pelo método Kjeldahl (FRAZIER e WESTHOFF, 1993).

$\mathrm{O} \mathrm{pH}$ foi medido potenciometricamente (AOAC, 1995). Usando o mesmo homogeneizado preparado para a determinação do $\mathrm{pH}$, a acidez titulável total foi determinada por titulação com $\mathrm{NaOH} 0,1 \mathrm{~N}$ em presença de solução alcoólica de fenolftaleína $1 \%$, com resultado expresso em ácido láctico $(\% \mathrm{p} / \mathrm{p})$.

\section{RESULTADOS E DISCUSSÃO}

A Tabela 1 apresenta os valores da composição química (umidade, cinzas, lipídios e proteínas) dos filés de sardinha (Sardinella brasiliensis) in natura. Com relação à percentagem de umidade, a variação situou-se na faixa correspondente aos peixes marinhos, entre 66 e 84\% (AQUARONE et al., 1983). São citados na literatura teores entre $70-80 \%$ e $64-90 \%$ (BADOLATO et al., 1994). A estação do ano afeta o conteúdo de umidade do pescado, o que já foi constatado por outros autores quando relacionaram a época de captura com a composição centesimal (LEWUS et al., 1991). $\mathrm{Na}$ determinação da umidade de cinco espécies marinhas, incluindo a sardinha, BADOLATO et al. (1994) encontraram valores entre 77,2 e 83,8\% para capturas no inverno de 1992. O resultado referente ao teor de lipídios (Tabela 1) também é coerente com a literatura (MULLER e TOBIN, 1991). Quanto aos lipídios, pesquisas mostraram que peixes de águas tropicais costumam apresentar teores muito inferiores aos do Hemisfério Norte (BERTULLO, 1975). Fato realmente constatado neste trabalho. A importância da variação sazonal é complexa, pois as sardinhas (Sardinella sp.) podem apresentar $2 \%$ de lipídios na primavera e até $8,6 \%$ no outono. As variações sazonais são atribuídas a espécies de plânctons predominantes em certas épocas do ano, havendo ainda a influência da idade do pescado. As sardinhas imaturas podem conter $3 \%$ de lipídios e aos 3 anos (fase de reprodução) entre 5 e 15\% conforme a estação do ano. 


\section{TABELA 1 - COMPOSIÇÃO QUÍMICA DOS FILÉS DA SARDINHA (Sardinella brasiliensis) IN NATURA}

\begin{tabular}{lccccc}
\hline & \multicolumn{5}{c}{ Composi ${ }^{\text {a }}$ o centesimal $(\mathrm{g} / 100 \mathrm{~g})$} \\
\cline { 2 - 6 } & $\mathrm{A}$ & $\mathrm{B}$ & $\mathrm{C}$ & $\mathrm{X}$ & $\mathrm{Dp}$ \\
\hline Umidade & 72,9 & 73,5 & 73,7 & 73,4 & $\pm 0,39$ \\
Lip dios & 2,0 & 3,0 & 4,2 & 3,1 & $\pm 0,89$ \\
Prote nas & 19,7 & 19,6 & 17,7 & 19,0 & $\pm 0,88$ \\
Cinzas & 2,0 & 1,9 & 1,9 & 1,9 & $\pm 0,01$ \\
\hline
\end{tabular}

A, B, C = Lotes.

$\mathrm{X}=$ média; $\mathrm{Dp}=$ Desvio padrão.

A Tabela 2 mostra os resultados da avaliação microbiológica da sardinha (Sardinella brasiliensis) in natura, relacionada com microrganismos indicadores de higiene ou processamento, contaminação fecal, manipulação e patogênicos entéricos de veiculação hídrica.

\section{TABELA 2 - AVALIAÇÃO MICROBIOLÓGICA DA SARDINHA (Sardinella brasiliensis) IN NATURA}

\begin{tabular}{|c|c|c|c|}
\hline \multirow[t]{2}{*}{ Microbiota } & \multicolumn{3}{|c|}{ Enumera ${ }^{a} o$} \\
\hline & A & B & C \\
\hline $\begin{array}{l}\text { Microrganismos aer bios } \\
\text { mes filos }\left(\mathrm{UFC}^{-1} \text { ) }\right.\end{array}$ & $3,5 \times 10^{2}$ & $1,1 \times 10^{4}$ & $4,4 \times 10^{3}$ \\
\hline Coliformes totais (NMP g ${ }^{-1}$ ) & $<3$ & $<3$ & $<3$ \\
\hline Coliformes fecais (NMP g ${ }^{-1}$ ) & $<3$ & $<3$ & $<3$ \\
\hline $\begin{array}{l}\text { Staphylococcus aureus } \\
\left.\text { (UFC } \mathrm{g}^{-1}\right)\end{array}$ & $<10^{2}$ & $<10^{2}$ & $<10^{2}$ \\
\hline Enterococcus (UFC g ${ }^{-1}$ ) & $3,5 \times 10^{2}$ & $3,5 \times 10^{2}$ & $3,5 \times 10^{2}$ \\
\hline Salmonella sp. & $\begin{array}{l}\text { Aus CFncia } \\
\text { em } 25 \mathrm{~g}\end{array}$ & $\begin{array}{l}\text { Aus Crncia } \\
\text { em } 25 \mathrm{~g}\end{array}$ & $\begin{array}{l}\text { Aus CFr cia } \\
\text { em } 25 \mathrm{~g}\end{array}$ \\
\hline
\end{tabular}

$\mathrm{A}, \mathrm{B}, \mathrm{C}=$ Lotes.

Devido ao tipo de pesca, o tempo decorrido entre a captura da sardinha e a sua descarga nos portos é menor que para as outras variedades de peixes. Desse modo, pode-se esperar que apresentem cargas bacterianas mais reduzidas. 
A contagem em placas (microbiota aeróbia viável), utilizada como indicador de higiene e/ou processamento, mostrou variações entre $3,5 \times 10^{2}$ e 1,1 x $10^{4} \mathrm{UFCg}^{-1}$. De acordo com o ICMSF (1990) os resultados indicam pescado com carga bacteriana normal das espécies marinhas tropicais. A Tabela 2 mostra resultados relacionados com o grupo dos coliformes totais e fecais, evidenciando práticas de higiene e sanidade adequadas, conforme padrões requeridos para o processamento desse alimento (MAZO, 1999). Utilizado como indicador de contaminação pós-processo ou das condições de sanificação das superfícies operacionais (BRASIL, 1998), a enumeração de Staphylococcus aureus mostrou número de células reduzidas. Apesar da ausência de referencial relacionado com a presença de Enterococcus (microbiota típica de animais de sangue quente ou frio), esse índice fornece indicativo de qualidade higiênico-sanitária (SNEATH, 1986). Os ressultados encontrados são desprezíveis, indicando matériaprima de qualidade aceitável. Todos os lotes (A, B e C) apresentaram resultados negativos com relação à detecção de Salmonella sp.

Os fenômenos de aparecimento e resolução da rigidez cadavérica são rápidos em peixes, porém o enrijecimento post mortem e a queda do $\mathrm{pH}$ são graduais (geralmente, de $\mathrm{pH} 7$ para 6 no caso do pescado magro e até 5,6 no músculo escuro do pescado gorduroso). É desejável que a conservação pelo frio ocorra o mais rápido possível em $\mathrm{pH}$ reduzido, possibilitando o aumento da vida de prateleira (LEWUS et al., 1991). Os resultados apresentados na Tabela 3 indicaram condições adequadas de conservação do pescado.

\section{TABELA 3 - VARIAÇÃO DO pH DA SARDINHA (Sardinella brasiliensis) IN NATURA}

\begin{tabular}{cccccc}
\hline & A & B & C & X & Dp \\
\cline { 2 - 6 } & 6,1 & 5,9 & 6 & 6 & $\pm 0,08$ \\
\hline
\end{tabular}

A, B, C: Lotes.

$\mathrm{X} \pm$ Dp: Média \pm Desvio padrão.

Os resultados morfotinturiais, decorrentes da observação microscópica dos isolados (Lactobacillus sakei $2 \mathrm{a}$ ), foram obtidos utilizando-se metodologia por esgotamento em estrias em meio semi - sólido, com incubação a $30^{\circ} \mathrm{C}$ por 24 horas. A linhagem apresentou-se como cocobacilos Gram-positivos, com forma regular, isolados e em pares, com 
ausência de esporos. A colônia isolada evidenciou coloração creme, com forma circular, superfície lisa, presença de brilho, com margem regular inteira, elevação convexa, consistência cremosa e tamanho entre 0,5 e $1 \mathrm{~mm}$. A caracterização do cultivo é mostrada na Tabela 4, com incubação a $30^{\circ} \mathrm{C}$ e leitura de crescimento até 48 horas. Em teste complementar, a linhagem apresentou-se como aerotolerante sem motilidade em meio semisólido. Trata-se de espécie homofermentativa, que cresce a 8 e $15^{\circ} \mathrm{C}$, mas não se desenvolve a $45^{\circ} \mathrm{C}$. Conforme BROCK (1974) sua característica indica espécie pertencente ao subgênero Streptobacterium.

\section{TABELA 4 - CARACTERIZAÇÃO FISIOLÓGICA DO Lactobacillus sakei 2a}

\begin{tabular}{cccccccc}
\hline & \multicolumn{2}{c}{ Halofilismo $(\% \mathrm{NaCl})$} & \multicolumn{3}{c}{ Crescimento $\left({ }^{\circ} \mathrm{C}\right)$} & \multicolumn{2}{c}{$\begin{array}{c}\text { Liquefa a o da } \\
\text { gelatina }\end{array}$} \\
3,9 & 6,5 & 7,0 & 10 & 8 & 15 & 45 & \\
\hline+ & + & + & $\mathrm{w}$ & + & + & - & - \\
\hline
\end{tabular}

(+) resultado positivo, (-) resultado negativo, (w) resultado positivo fraco.

A caracterização do $L$. sakei 2a segue o descrito por SNEATH (1986) para o gênero Lactobacillus, o qual raramente apresenta motilidade. Pode crescer em superfícies de meios semi-sólidos, por anaerobiose ou sob pressão reduzida de oxigênio entre $5-10 \%$ de $\mathrm{CO}_{2}$ e não liquefaz a gelatina. É acidófilo, com crescimento em pH 5 ou menos e temperaturas entre 2 e $53^{\circ} \mathrm{C}$.

GONZÁLEZ-FERNANDEZ et al. (1997), estudando a influência de cultivos iniciadores relacionados com as propriedades sensoriais de lingüiça tipo frescal, complementaram suas pesquisas caracterizando 2 cepas de Lactobacillus sakei e uma de Pediococcus sp. As linhagens isoladas de L. sakei também apresentaram crescimento em pH 3,9 e concentrações salinas entre 7 e $10 \%$ de $\mathrm{NaCl}$. Tais autores estudaram a fermentação dessas cepas sobre carboidratos mediante ensaios semelhantes aos mostrados na Tabela 5. Duas cepas de L. sakei, pesquisadas, não apresentaram atividade fermentativa sobre arabinose, celobiose, maltose, ramnose e rafinose. Deve-se considerar que essas linhagens não produziram bacteriocinas.

A Figura 1 mostra a influência da concentração salina (2, 4 e 6\% de $\mathrm{NaCl})$ sobre o pH da sardinha submetida à cura na ausência da glicose e do 
starter. Com 2 dias de fermentação, o pH manteve-se em 5,9 (2\% de $\mathrm{NaCl}), 5,7(4 \%$ de $\mathrm{NaCl})$ e 5,5 (6\% de $\mathrm{NaCl})$. Com 4 dias, o $\mathrm{pH}$ atingiu 6,9 (2\% de $\mathrm{NaCl}), 6,6(4 \%$ de $\mathrm{NaCl})$ e 6 (6\% de $\mathrm{NaCl})$. Já aos 5 dias de fermentação ( $6 \%$ de $\mathrm{NaCl}$ ) o pH atingiu 6,6. Considerando a disponibilidade de nutrientes, conjugado com a elevada atividade de água e processamento em temperatura ambiente $\left(23-24^{\circ} \mathrm{C}\right)$, o poder tampão do substrato fez com que $0 \mathrm{pH}$ se elevasse em direção à faixa alcalina, permitindo 0 metabolismo e a completa deterioração microbiana.

\section{TABELA 5 - CARACTERIZAÇÃO BIOQUÍMICA DO Lactobacillus sakei 2a}

\begin{tabular}{|c|c|c|c|}
\hline Produ ${ }^{a} 0$ & $\begin{array}{l}\text { Rea a o ou } \\
\text { crescimento }\end{array}$ & Fermenta $\stackrel{a}{\circ} 0$ & $\begin{array}{l}\text { Rea }{ }^{a} \text { o ou } \\
\text { crescimento }\end{array}$ \\
\hline Catalase & - & Lactose & - \\
\hline Aceto na & + & Sacarose & + \\
\hline GAs de glicose & - & Glicose & + \\
\hline $\mathrm{H}_{2} \mathrm{~S}$ & - & Ramnose & - \\
\hline Indol & - & Xilose & - \\
\hline Descarboxila a o da lisina & + & Arabinose & + \\
\hline Teste vermelho de metila & + & Rafinose & - \\
\hline \multirow[t]{4}{*}{ Bacteriocinas } & + & Galactose & + \\
\hline & & Maltose & - \\
\hline & & Trealose & - \\
\hline & & Sorbitol & - \\
\hline
\end{tabular}

$(+)=$ positivo $\quad(-)=$ negativo

A adição da glicose ao processo foi necessária para promover adequada fermentação, pois o peixe apresenta reduzido teor de carboidratos livres. Os carboidratos encontram-se fundamentalmente no músculo e fígado, representados por pequenas quantidades de polissacarídios glicogênicos. O conteúdo de glicogênio no tecido muscular varia entre 0,05 e 0,85\% (FRAZIER e WESTHOFF, 1993), o que o torna sem efeito no processo fermentativo. $O$ amido com diferentes graus de geleificação e degradação é usado na maioria dos produtos tradicionais, porém poucas bactérias ácido láticas têm sido identificadas como produtoras de amilase. A eficiência da fermentação láctica foi monitorada pela relação entre o decréscimo do $\mathrm{pH}$ com a correspondente elevação da acidez e o balanço entre a enumeração das bactérias ácido láticas (BAL) em MRS e deterioradoras em PCA.

O baixo crescimento das bactérias ácido láticas (BAL) em PCA facilita a exclusão do total das bactérias deterioradoras, possibilitando as correspondentes enumerações traduzidas pela competição entre ambas. 
O resultado das análises físico-químicas indicaram que houve decréscimo do $\mathrm{pH}$ durante o desenvolvimento da fermentação, com tendência à estabilização entre 3,8 e 4,2, após 21 dias (Tabela 6). Uma das causas do efeito do rebaixamento inicial do $\mathrm{pH}$ seria a produção de ácido a partir do starter inoculado, inibindo a multiplicação da carga microbiana de deterioração e permitindo a seqüência da fermentação. Com decréscimo do $\mathrm{pH}$ para valores inferiores a 4,4 (Tabela 6), no início da fermentação a microbiota lática multiplica-se rapidamente, resultando em redução imediata ainda maior. Mecanismo inespecífico, a produção de ácido afeta todas as bactérias acidossensíveis indiscriminadamente. GORY et al. (2001) mencionam esse comportamento na avaliação do crescimento de três cepas de $L$. sakei (duas geneticamente modificadas), associado à produção de lactato e variação de $\mathrm{pH}$. O valor inicial do $\mathrm{pH}(5,6)$ decresceu para 4,2 a $30^{\circ} \mathrm{C} \mathrm{e} 4,4$ a $22^{\circ} \mathrm{C} \mathrm{em} 24$ horas.

\section{FIGURA 1 - INFLUÊNCIA DA CONCENTRAÇÃO SALINA SOBRE O pH DA SARDINHA SUBMETIDA AO PROCESSO DE CURA, NA AUSÊNCIA DA GLICOSE E STARTER. O EFEITO SOBRE O PH INICIAL DO SUBSTRATO FOI COMPARADO PELA ADIÇÃO DE 2\% DE NaCl (A), 4\% DE NaCl (B) E 6\% $\mathrm{DE} \mathrm{NaCl}(\mathrm{C})(\mathrm{P} / \mathrm{P})$}
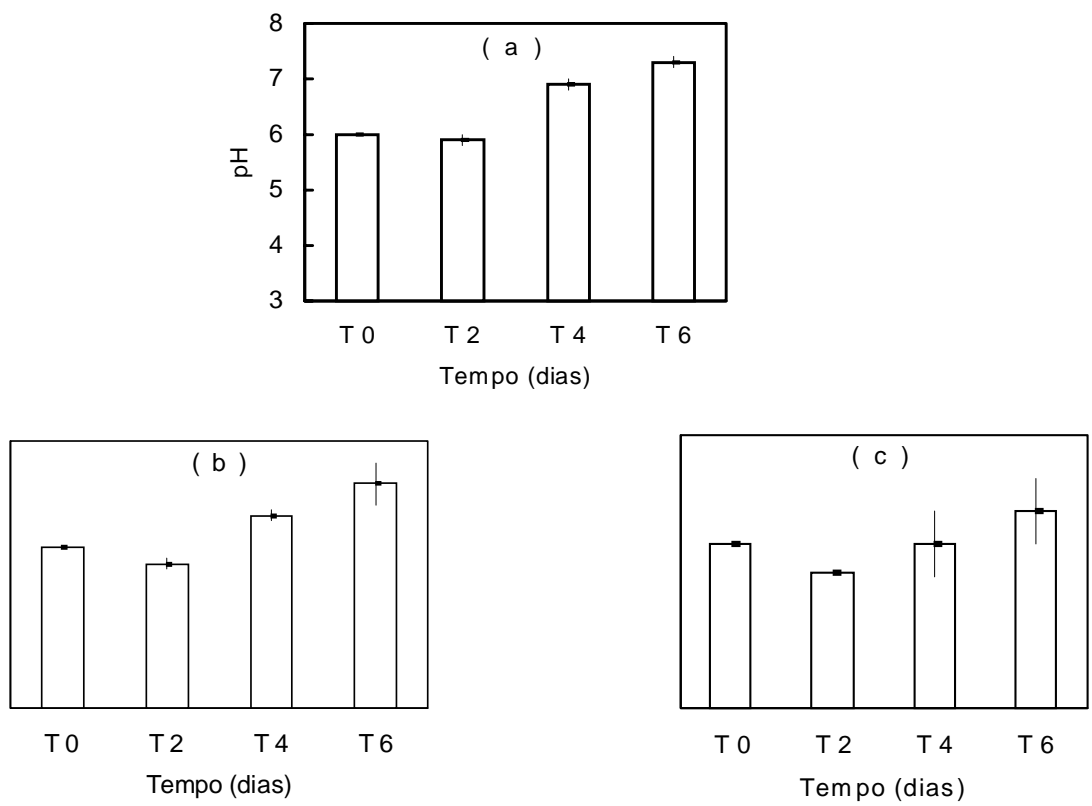


\section{TABELA 6 - EFEITO DA GLICOSE E NaCI SOBRE O VALOR DO pH NA FERMENTAÇÃO DA SARDINHA PELO Lactobacillus sakei 2a}

\begin{tabular}{ccccccc}
\hline \multirow{2}{*}{$\begin{array}{c}\text { Tempo } \\
\text { (dias) }\end{array}$} & \multicolumn{3}{c}{$2 \%$ glicose } & & \multicolumn{3}{c}{$4 \%$ glicose } \\
\cline { 2 - 6 } & $2 \%$ & $\begin{array}{c}\mathrm{NaCl} \\
4 \%\end{array}$ & $6 \%$ & $2 \%$ & $\begin{array}{c}\mathrm{NaCl} \\
4 \%\end{array}$ & $6 \%$ \\
\hline 0 & 6,0 & 6,0 & 6,0 & 6,0 & 6,0 & 6,0 \\
7 & 4,1 & 4,2 & 4,3 & 4,0 & 4,1 & 4,2 \\
14 & 4,1 & 4,2 & 4,3 & 4,0 & 4,0 & 4,1 \\
21 & 4,0 & 4,1 & 4,2 & 3,8 & 3,9 & 4,0 \\
\hline
\end{tabular}

A Tabela 7 mostra a produção de ácido lático, reproduzindo os tratamentos com aplicação do starter associado a 2 e $4 \%$ de glicose e a 2, 4 e $6 \%$ de $\mathrm{NaCl}$. Pode-se observar que com a adição de $2 \%$ de glicose e $2 \%$ de $\mathrm{NaCl}$, a acidez após 21 dias apresentou o valor máximo (2,55\%). Com $4 \%$ de glicose e equivalente teor salino atingiu 2,64\%. Quando se agrega $2 \%$ de glicose e $2 \%$ de $\mathrm{NaCl}$ o $\mathrm{pH}$ da sardinha decresce para $4,1 \mathrm{em} 7$ dias e para 4 em 21 dias. Reciprocamente, a acidez aumenta para 1,21 e $2,55 \%$, respectivamente. Com $4 \%$ de glicose e $2 \%$ de $\mathrm{NaCl}$, o $\mathrm{pH}$ da sardinha decresce para $4 \mathrm{em} 7$ dias e para 3,8 em 21 dias. Por sua vez, a acidez aumenta para 1,77\% (7 dias) e 2,76\% (21 dias). Contrariamente, na ausência da glicose e, considerando as 3 concentrações salinas $(2,4$, e $6 \%$ de $\mathrm{NaCl}$ ), a acidez mostrou tendência à queda, comprovada pela deterioração do pescado com 6 dias de processamento. Trabalhos similares mostram que os comportamentos do $\mathrm{pH}$ e da acidez não diferem. ADAMS et al. (1987), estudando a avaliação do ácido lático na preservação de truta (Salmo truta), monitoraram a eficiência da fermentação com tratamentos envolvendo starters comerciais compostos por cepas de $L$. plantarum e $P$. pentosaceus. Tais autores evidenciaram relação de rebaixamento do $\mathrm{pH}$ com a adição de $5 \%$ de sacarose. $\mathrm{O}$ aumento na concentração de $\mathrm{NaCl}(6 \%)$ também reduziu a relação de fermentação. Utilizando $1 \%$ de $\mathrm{NaCl}, 4 \%$ glicose e L. plantarum houve redução de pH para 5,4 nas primeiras 24 horas e para 4,2 após 4 dias. Com 2 e $3 \%$ de $\mathrm{NaCl}$ houve baixa fermentação durante os 3 primeiros dias, o pH manteve-se entre 6 e 6,5 após 24 horas e atingiu 4,2 com 4 dias de fermentação. Com 4 a $6 \%$ de $\mathrm{NaCl}$, o pH manteve-se em torno de 6,5 , com incubação de 7 dias. A repetição com diferentes tratamentos mostrou diferenças no período mais importante, os 2 primeiros dias de 
fermentação. Tal fato pode refletir as diferenças entre os graus de frescor do peixe, afetando a relação entre as bactérias ácido láticas e a microbiota competidora.

Os resultados apresentados na Tabela 8 indicaram rápida fermentação lática do substrato (peixe). A contagem em MRS, a partir do sétimo dia de fermentação e até o vigésimo primeiro, excedeu a dos deterioradores entre $1 \log _{10}$ UFC g-1 e $5 \log _{10}$ UFC g-1. A relação de fermentação foi maior em todos os tratamentos quando se considera a utilização de $4 \%$ de glicose, proporcionando diferença na contagem em MRS de pelo menos $1 \log _{10}$ UFC g-1 $^{-1}$. Muitos carboidratos, incluindo os amiláceos, são bons substratos para as BAL e o uso desse tipo de nutriente pode provocar grande atividade lática. Os principais carboidratos que podem ser utilizados nestas fermentações incluem o arroz cozido e o pré-fermentado ou farináceos de mandioca (TWDDY et al., 1987).

TABELA 7 - EFEITO DA GLICOSE E NaCI SOBRE O VALOR DA ACIDEZ, DURANTE A FERMENTAÇÃO DA SARDINHA PELO Lactobacillus sakei2a

\begin{tabular}{ccccccc}
\hline & \multicolumn{3}{c}{$2 \%$ glicose } & \multicolumn{3}{c}{$4 \%$ glicose } \\
\cline { 2 - 7 } $\begin{array}{c}\text { Tempo } \\
\text { (dias) }\end{array}$ & $2 \%$ & $4 \%$ & $6 \%$ & $2 \%$ & $4 \%$ & $6 \%$ \\
\hline 0 & 0,48 & 0,48 & 0,48 & 0,48 & 0,48 & 0,48 \\
7 & 1,21 & 1,12 & 0,74 & 1,77 & 1,42 & 0,79 \\
14 & 1,73 & 1,60 & 1,22 & 2,55 & 2,23 & 1,32 \\
21 & 2,55 & 2,23 & 1,32 & 2,76 & 2,64 & 1,34 \\
\hline
\end{tabular}

TABELA 8 - EFEITO DA GLICOSE E NaCI NO CRESCIMENTO DAS BACTÉRIAS ÁCIDO LÁTICAS EM MRS (LOG ${ }_{10}$ UFC g-1) $^{-1}$ DURANTE A FERMENTAÇÃO DA SARDINHA PELO Lactobacillus sakei $2 \mathrm{a}$

\begin{tabular}{crrrrrr}
\hline & \multicolumn{3}{c}{$2 \%$ glicose } & \multicolumn{3}{c}{$4 \%$ glicose } \\
\cline { 2 - 7 } $\begin{array}{c}\text { Tempo } \\
\text { (dias) }\end{array}$ & $2 \%$ & $\begin{array}{c}\mathrm{NaCl} \\
4 \%\end{array}$ & $6 \%$ & $2 \%$ & $\begin{array}{c}\mathrm{NaCl} \\
4 \%\end{array}$ & $6 \%$ \\
\hline 0 & 5,2 & 5,2 & 5,2 & 5,2 & 5,2 & 5,2 \\
7 & 11,6 & 9,9 & 8,9 & 11,6 & 11,0 & 9,8 \\
14 & 13,6 & 13,2 & 11,9 & 14,6 & 13,6 & 12,9 \\
21 & 14,2 & 14,0 & 12,9 & 15,3 & 15,0 & 14,5 \\
\hline
\end{tabular}


ADAMS et al. (1987) estudaram a fermentação espontânea de peixes com adição de glicose e $\mathrm{NaCl}$. Avaliaram diversos fatores que favorecem a rápida fermentação lática como o decréscimo do $\mathrm{pH}$ para valores inferiores a 4,5 nas primeiras 48 horas e a eficiência da multiplicação das BAL com decréscimo dos microrganismos deterioradores. Os estudos com Lactobacillus plantarum e Pediococcus pentosaceus mostraram que a relação de fermentação aumenta conforme o teor de glicose ou sacarose utilizado (entre 1 e 5\%). Entretanto, o aumento na concentração salina provoca redução no crescimento desses microrganismos com conseqüente diminuição na velocidade de fermentação. Tais autores afirmaram que cada fermentação depende da microbiota acompanhante, da composição do alimento, da atividade de água, do pH, da concentração de $\mathrm{NaCl}$ e da temperatura de processo.

FIGURA 2 - VARIAÇÕES NA CONTAGEM TOTAL DE MICRORGANISMOS SOBRE PCA (LOG 10 UFC g-1) DURANTE A FERMENTAÇÃO DA SARDINHA PELO Lactobacillus sakei 2a, COM 2\% E $4 \%$ de GLICOSE. 0 EFEITO FOI COMPARADO PELA ADIÇÃO DE 2, 4 e 6\% $\mathrm{DE} \mathrm{NaCl}$
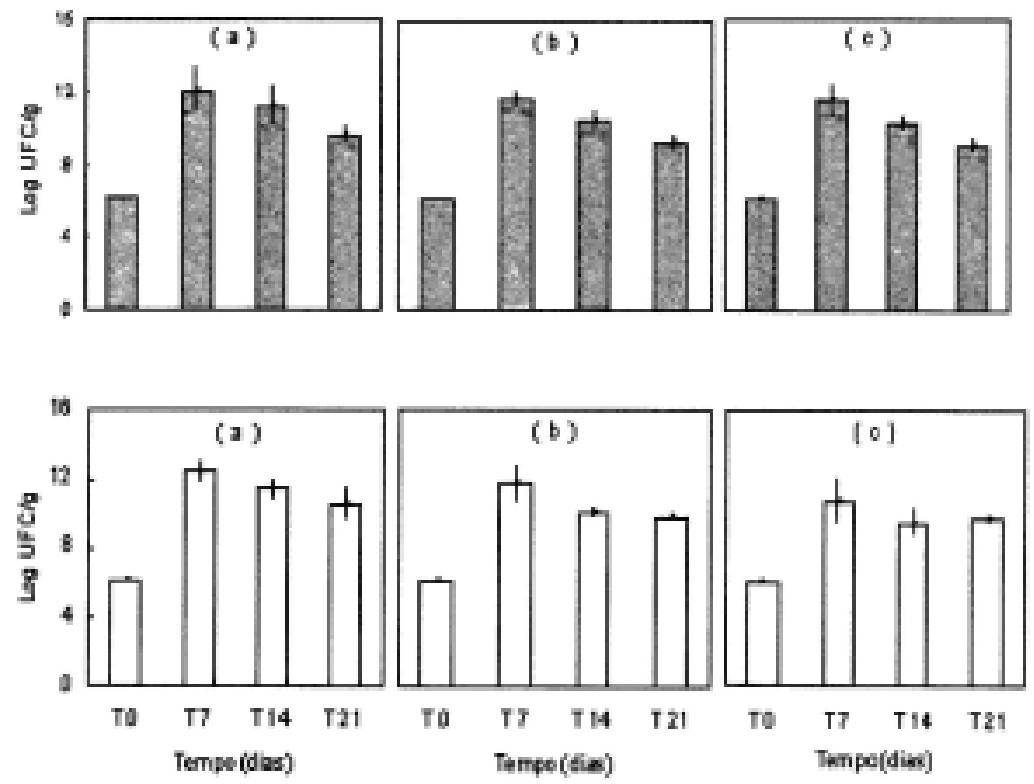

$\square-2 \%$ de glicose, - $4 \%$ de glicose.

(a) $=2 \% \mathrm{NaCl},(\mathrm{b})=4 \% \mathrm{NaCl},(\mathrm{c})=6 \% \mathrm{NaCl}$. 
O conteúdo de nitrogênio protéico do sobrenadante de todas as amostras aumentou com o tempo de fermentação. Amostras contendo $2 \%$ de $\mathrm{NaCl}$ mostraram valores maiores do que aquelas contendo $6 \%$, independente do teor de glicose utilizado. O aumento do conteúdo de nitrogênio protéico pode ser atribuído ao efeito combinado da autólise e degradação microbiana do músculo do peixe. A evidência para a autólise neste experimento pode ser demonstrada pela variação na relação do nitrogênio protéico (NP) para o nitrogênio solúvel total (NST) (Figura 3). Tal relação aumentou durante o período de fermentação.

\section{FIGURA 3 - EVIDÊNCIA DA AUTÓLISE DURANTE A FERMENTAÇÃO DA SARDINHA (Sardinella brasiliensis) PELO Lactobacillus sakei $2 a$}

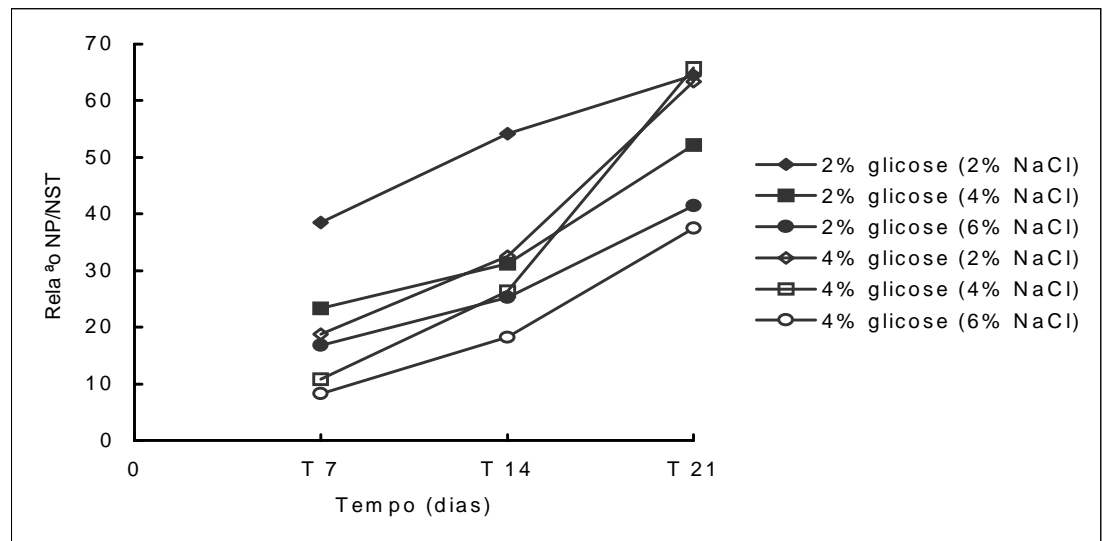

A utilização de Lactobacillus e Streptococcus na fermentação de resíduos de pescado, como alternativa para produção de alimentação animal foi pesquisada por ARECHE e BERENZ (1989). Demonstraram a eficácia das bactérias associada com as mudanças nas características físicoquímicas e microbiológicas do pescado. Nas primeiras 24 horas de fermentação, os inóculos adicionados em diferentes concentrações (2,5 e $10 \%$ ) ocasionaram ligeiro aumento das bases voláteis nitrogenadas e em especial da histamina. Posteriormente, as concentrações destes compostos foram diminuindo lentamente, contribuindo para a redução do nitrogênio solúvel total, com decréscimo significativo e constante durante as 300 horas de processamento. De modo semelhante, os resultados relacionados com o nitrogênio solúvel total (NST) obtidos com a fermentação da sardinha evidenciaram controle natural da fermentação. 
A atividade do startersugere reação amino-negativa, prevenindo a formação de aminas durante o processo de fermentação. É possível que também reduza a atividade de bactérias descarboxilases na formação de aminas biogênicas, contribuindo para a redução do nitrogênio solúvel total. Os riscos microbiológicos na fermentação da sardinha (Sardinella brasiliensis) estão sempre associados à formação de histamina (ROIG-SAGUÉS e EEROLA, 1997; SILVA et al., 1998).

ROIG-SAGUÉS e EEROLA (1997) adotaram critérios de seleção para a utilização de bactérias ácido láticas em alimentos. Mencionaram que a ocorrência de aminas biogênicas é previsível nos produtos, principalmente nos fermentados espontaneamente por microbiota indefinida, e que a seleção de starter apropriado reduzirá a formação de aminas biogênicas. Esses autores também estudaram a formação de bases aminadas em carne picada inoculada com Lactobacillus sakei. Demonstraram que o efeito do starter depende da presença de microrganismos descarboxilases na matéria-prima e que os efeitos são diferentes para cada amina produzida.

\section{CONCLUSÃO}

O estudo indicou que Lactobacillus sakei 2a constitui cepa apropriada para a fermentação da Sardinha-verdadeira (Sardinella brasiliensis). As condições de processamento foram mais favoráveis para esse lactobacilo, com conseqüente inibição do crescimento das bactérias deterioradoras.

Bactérias ácido láticas com características bacteriocinogênicas e competitivas podem promover barreira adicional para aumentar a preservação do pescado por meios naturais. A implementação da biopreservação em determinados sistemas alimentares sempre dependerá da formulação, da tecnologia utilizada, da viabilidade da cultura na produção de bacteriocinas como também da adaptação das culturas aos meios (alimentares) específicos.

\section{Abstract}

EVALUATION OF BACTERIOCINOGENIC ACTIVITY OF Lactobacillus sakei IN THE FERMENTETION OF TRUE SARDINE (Sardinella brasiliensis) BY UTILIZING GLUCOSE AS FERMENTABLE CARBOHYDRATE

Lactobacillus sakei $2 \mathrm{a}$ is a bacteriocin producer strain and, in this study, it's effects as a starter culture in the curing process of sardine (Sardinella brasiliensis) fillets were observed at different concentrations of sodium chloride and glucose. It's ability to produce organic acids and $\mathrm{pH}$ reduction during 21 days of fermentation was verified. After this 
period, the deteriorative microbiota concentration reached $9.7 \log _{10}$ CFU. $g^{-1}$ corresponding to $6 \%$ sodium chloride and $4 \%$ glucose. Little differences were observed in lactic acid production when 2 and $4 \%$ glucose were added, since total acidity was 1.32 and $1.34 \%$ respectively for the experiments with $6 \% \mathrm{NaCl}$. Initial pH of fillets was 6 and after 21 days $\mathrm{pH}$ values were $3.8,3.9$ and 4 for the experiments with 2,4 and $6 \% \mathrm{NaCl}$. This may have been due to the inhibitory properties of $\mathrm{NaCl}$ over the deteriorative microbiota. At the end of the fermentation process lactic acid bacteria concentrations were $14.5 \log _{10}$ CFU. $\mathrm{g}^{-1}$. The ratio protein nitrogen and total soluble nitrogen was typical of a cured fish under perfect eating conditions.

KEY-WORDS: SARDINE FILLETS-FERMENTATION; CURED FISH; Lactobacillus sakei.

\section{REFERÊNCIAS}

1 ADAMS, M.R.; COOKE, R.D.; TWIDDY, D.R. Fermentation parameters involved in the production of lactic acid preserved fish-glucose substrates. International Journal of Food Science and Technology, Oxford, v.22, n.2, p.105-114, 1987.

2 AOAC. ASSOCIATION OF OFFICIAL ANALYTICAL CHEMISTS. Official methods of analysis AOAC international. $16^{\text {th }}$ ed. Washington, $1995.1141 \mathrm{p}$.

3 APHA. AMERICAN PUBLIC HEALTH ASSOCIATION. Compendium of methods for the microbiological examination of foods. $3^{\text {rd }}$ ed. Washington, 1992. $1219 \mathrm{p}$.

4 AQUARONE, E.; ALMEIDA LIMA, U.; BORZANI, W. Alimentos e bebidas produzidos por fermentação. São Paulo: E. Blücher, 1983. 227 p.

5 ARECHE, T. N.; BERENZ, Z. Ensilado de residuos de pescado por bacterias del yogur. Boletin de Investigación - Instituto Tecnologico Pesquero del Peru, Callao, v.3, p. 26-36, 1989.

6 BADOLATO, E.S.G.; CARVALHO, J.B.; AMARAL MELLO, M.R.P.; TAVARES, M.; CAMPOS, N.C.; AUED-PIMENTEL, S.; MORAIS, C. Composição centesimal de ácidos graxos e valor calórico de cinco espécies de peixes marinhos nas diferentes estações do ano. Revista do Instituto Adolfo Lutz, São Paulo, v.54, n1, p.27-35, 1994.

7 BERTULLO, V.H. Tecnologia de los productos y subproductos de pescados, moluscos y crutáceos. Buenos Aires: Hemisferio Sur, 1975. 538 p.

8 BRASIL. Ministério da Saúde. Secretaria de Vigilância Sanitária. Portaria n. 451 de 1997. Princípios gerais para o estabelecimento de critérios e padrões microbiológicos para alimentos. Diário Oficial [da] República Federativa do Brasil, Brasília, 2 de julho de 1998. p. 6.

9 BROCK, T.D. Biology of microorganisms. $5^{\text {th }}$ ed. New Jersey: Prentice-Hall, 1974. p. 697-704.

10 DE MARTINIS, E.C.P.; FRANCO, B.D.G.M. Inhibition of foodborne by bacteriocinproducing Leuconostoc spand Lactobacillus sakei isolated from "lingüiça frescal". Revista de Microbiologia, São Paulo, v.28, n.4, p.284-287, 1998.

11 FAO. FOOD AND AGRICULTURE ORGANIZATION OF THE UNITED NATIONS. Manual de técnicas para laboratório de nutricion de peces y crustceos. Programa cooperativo goviernamental. Mexico, 1993. 104 p. 
12 FRAZIER, W.C.; WESTHOFF, D.C. Microbiología de los alimentos. Zaragoza: Acribia, 1993. 681 p.

13 GONZÁLES-FERNANDEZ, C.; SANTOS, E.M.; JAIME, I.; ROVIRA, J. Utilización de cultivos iniciadores en la elaboración de chorizo y su influencia en las propriedades sensoriales. Food Science and Technology International, New York, v.3, n.1, p.31-42, 1997.

14 GORY, L.; MONTEL, M.C.; ZAGOREC, M. Use of green fluorescent protein to monitor Lactobacillus sakei in fermented meat products. Federation of European Microbiological Societies - Microbiology Letters, Amsterdam, v.194, n.2, p.127133, 2001.

15 ICMSF. International Comission on Microbiological Specifications For Foods. Microorganisms in foods: their significance and methods for enumeration. $3^{\text {rd }}$ ed. Toronto, 1990.

16 LEWUS, C.B.; KAISER, A.; MONTVILLE, T.J. Inhibition of food-borne bacterial pathogens by bacteriocins from lactic acid bacteria isolated from meat. Applied and Environmetal Microbiology, Washington, v.57, p.1683-1688, 1991.

17 LINDEN, G.; LORIENT, D. Bioquímica agroindustrial: revalorización alimentaria de la producción agrícola. Zaragoza: Acribia, 1994. 428 p.

18 LISTON, J. Microbiology in fishery science. In: CONNELL, J.J. Advances in fish science and technology. Aberdenn: Fishing News Books, 1979. p.138-157.

19 MAZO, J.Z. Detecção de bacteriocinas produzidas por Lactobacillus plantarum BN em melaço de cana-de-açúcar sob fermentação submersa. Florianópolis, 1999. 46 p. Dissertação (Mestrado em Ciência dos Alimentos) - Centro de Ciências Agrárias, Universidade Federal de Santa Catarina.

20 MULLER, H.G.; TOBIN, G. Nutrición y ciencia de los alimentos. Zaragoza: Acribia, 1991. 321 p.

21 PIGOTT, G.M.; TUCKER, B.W. Seafood: effects of technology on nutrition. New York: Marcel Dekker, 1990. p. 32-65.

22 ROBINSON, D.S. Bioquímica y valor nutritivo de los alimentos. Zaragoza: Acribia, 1991. 516 p.

23 ROIG-SAGUÉS, A.; EEROLA, S. Biogenic amines in meat inoculated with Lactobacillus sakei starter strains and an amine-positive lactic acido bacterium. Food Research and Technology, New York, v. 205, n.3, p.227-231, 1997.

24 SILVA, C.C.G.; DA PONTE, J.B.; DAPKEVICIUS, M.L.N.E. Storage temperature effect on histamine formation in big eye tuna and skipjack. Journal of Food Science, Chicago, v.63, n.4, p.644-647, 1998.

25 SILVA, N.; JUNQUEIRA, V.C.A.; SILVEIRA, N.F.A. Manual de métodos de análise microbiológica de alimentos. São Paulo: Varela, 1997. 295 p.

26 SNEATH, P.H.A. Regular, nonsporing Gram-positive rods. In: BERGEY'S manual of systematic bacteriology. Baltimore: Williams e Wilkins, 1986. v. 2.

27 TWDDY, D.R.; CROSS, S.J.; COOKE, R.D. Parameters involved in the production of lactic acid preserved fish-starchy substrate combinations. International Journal of Food and Technology, Mysore, v.22, p.115-121, 1987. 